\title{
SURGICAL OUTCOME OF DISTAL FEMORAL FRACTURES TREATED WITH LOCKING COMPRESSION PLATE- A PROSPECTIVE STUDY
}

\author{
Jenson Isaac ${ }^{1}$, Vijay Krishna², Sowmiya K. $R^{3}$ \\ ${ }^{1}$ Associate Professor, Department of Orthopaedics, Tagore Medical College and Hospital, Chennai, Tamilnadu, India. \\ ${ }^{2}$ Senior Resident, Department of Orthopaedics, Tagore Medical College and Hospital, Chennai, Tamilnadu, India. \\ 3Professor, Department of Community Medicine, Tagore Medical College and Hospital, Chennai, Tamilnadu, India.
}

\begin{abstract}
BACKGROUND

Distal femoral fractures of femur are one of the most challenging injuries to treat. Because of the proximity of these fractures to the knee joint, regaining full knee motion and function may be difficult. Closed management of these distal femoral fractures thus poses difficulties in obtaining and maintaining the reduction making operative management the preferred treatment. Hence the aim of the study is to analyze the short-term results in terms of union and functional outcome for distal femoral fractures treated with distal femoral locking compression plating.
\end{abstract}

\section{METHODS}

This is a prospective study conducted in the Department of Orthopaedics, Tagore Medical College and Hospital, Chennai from January 2017 to January 2019 with a sample size of 50 cases based on the inclusion and exclusion criteria.

\section{RESULTS}

The total number of patients was 50 with 30 males and 20 females. The youngest age in our study was 19 and the oldest age is 65 . Modes of injury were- 40 cases due to RTA, 6 cases due to accidental fall and 4 case due to fall of heavy object. The average months of follow up were 10. 6 months with longest of 23 months and shortest of 3 months. Average time to union was 18 weeks with a range from 10 weeks to 36 weeks. Mean range of motion was $0^{0}-106.8^{0}$. Using the HSS scoring system, $72 \%$ had good to excellent results.

\section{CONCLUSIONS}

In our study, the results are encouraging with $72 \%$ of the patients having good to excellent results. Therefore, locking compression plate has a significant advantage with excellent results in treating distal femoral fractures. However, accurate positioning and fixation are required to produce satisfactory results.

\section{KEY WORDS}

LCP, Distal Femoral Fractures, HSS, Mullers AO-ASIF Classification

HOW TO CITE THIS ARTICLE: Isaac J, Krishna V, Sowmiya KR. Surgical outcome of distal femoral fractures treated with locking compression plate- a prospective study. J. Evolution Med. Dent. Sci. 2019;8(25):1969-1973, DOI: 10.14260/jemds/2019/433

\section{BACKGROUND}

Supracondylar fractures of the femur are becoming more common and are very challenging injuries to treat. ${ }^{1-3}$ These fractures occur in two different age groups -due to different types of injuries. In young patients these fractures occur due to high velocity injury such as road traffic accidents, fire arm injuries and sports injuries. While in elderly patients usually low velocity injury like fall during walking, results in supracondylar fractures of the femur. ${ }^{4-7}$

Because of the proximity of these fractures to the knee joint, regaining full knee motion and function may be difficult. The incidences of malunion, non-union, and infection are relatively high in many reported series.8-10 In older patients, treatment may be complicated by previous joint arthroplasty.

'Financial or Other Competing Interest': None.

Submission 18-05-2019, Peer Review 12-06-2019,

Acceptance 15-06-2019, Published 24-06-2019.

Corresponding Author:

Jenson Isaac,

Flat No. 4041

Estancia Township,

Guduvanchery,

Chennai-603202, Tamilnadu, India.

E-mail: docjenson@gmail.com

DOI: $10.14260 /$ jemds $/ 2019 / 433$

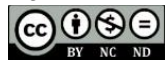

There are multiple options for the treatment of these fractures with their associated merits and demerits. Anatomical restoration of the knee joint congruity, proper alignment and secure fixation of both proximal and distal fragments are the key to achieve good functional outcome in these fractures to prevent early secondary osteoarthritis. Hence this study was taken up to assess the surgical outcome of distal femoral fractures treated with locking compression plate during a period of two years at a tertiary care center in Chennai.

\section{METHODS}

This is a prospective study conducted in the Department of Orthopaedics, Tagore Medical College and Hospital, Chennai from January 2017 to January 2019.

\section{Inclusion Criteria}

1. Age more than 16 years.

2. Patients with distal femoral fractures which needs to be internally fixed in displaced Muller's type A, type B and type $\mathrm{C}$ fractures.

3. Patient who is preoperatively mobile.

\section{Exclusion Criteria}

1. Skeletal immaturity with open physis.

2. Undisplaced fracture patterns needing only conservative management. 
3. Supracondylar fracture femur associated with other fractures.

\section{Study Protocol}

A total of 50 patients with distal femoral fractures were included in the study as per the inclusion criteria outlined previously. On admission detailed examination of the patients was carried out after hemodynamic stabilization. Then standard Antero-Posterior and Lateral view X-Rays are taken, and the fracture configuration noted. Computerized Tomography is also taken when needed to assess the exact alignment of the fragments. The fracture is classified using the following classification.

\section{Classification}

The classification of distal femoral fractures described by Müller et al. and expanded in the AO/OTA classification is useful in determining treatment and prognosis. It is based on the location and pattern of the fracture and considers all fractures within the trans epicondylar width of the knee.

\section{AO-ASIF Classification of Supracondylar Femur Fractures (Muller's) ${ }^{11}$}

Type A: Extra-articular fracture.

A1-Simple.

A2-Metaphyseal, wedge.

A3-Metaphyseal, complex.

Type B: Partial articular fracture.

B1-Lateral condyle (Sagittal fracture line).

B2-Medial condyle (Sagittal fracture line).

B3-Frontal (Coronal fracture line).

Type C: Complete articular fracture.

C1-Articular and metaphyseal segments, simple fractures.

C2-Articular simple, but metaphyseal multi fragmentary fractures.

C3-Articular and metaphyseal segments, multi fragmentary fractures.

Then after the assessment for anaesthetic fitness open reduction and internal fixation of the fracture is done using the distal femoral locking compression plate through the lateral approach under spinal anaesthesia.

The plate system has many similarities to traditional plate fixation methods with few improvements such as-

1. The screws do not rely on plate bone compression.

2. Multiple screw fixation in distal femoral condyle allows improved fixation in Type C3 fractures.

3. Anatomically shaped distal end is contoured to match the distal femur and hence intra-operative contouring is not required.

4. Combi-holes have additional dynamic compression holes providing options for axial compression in addition to locking mechanism.

5. Lateralisation of proximal femur is prevented by maintaining a gap between the proximal fragment and the plate until locking screw is applied after which the alignment is maintained.

\section{Swashbuckler Approach to Distal Femur.12-14}

Place the patient supine, preferably on a radiolucent table. Use a sterile tourniquet only if necessary, to avoid medial retraction of the quadriceps. Place a roll or triangle under the knee. Make a lateral incision from above the fracture laterally to across the patella. Extend the incision directly down to the fascia of the quadriceps. Incise the quadriceps fascia in line with the skin incision. Sharply dissect the quadriceps fascia off the vastus lateralis muscle laterally to its inclusion with the iliotibial band. Retract the iliotibial band and fascia laterally, continuing the dissection down to the linea aspera. Incise the lateral parapatellar retinaculum, separating it from the vastus lateralis. Make a lateral parapatellar arthrotomy to expose the femoral condyles. Place a retractor under the vastus lateralis and medialis, exposing the distal femur and displacing the patella medially. Ligate the perforating vessels, and elevate the vastus lateralis, exposing the entire distal femur. Proceed with the internal fixation as needed. Close the wound by suturing the fascia back in place with suction drain.

Demographic data (Age, gender and profession), mechanism of injury, severity of the injury (AO classification, open or closed fracture), associated injuries (Injury severity score), initial management and time to definitive treatment were recorded. Intra-operative events and difficulties, use of bone graft, post-operative local or systemic complications, time to union and time required to return to pre-injury activities were documented. All patients at their final assessment, underwent radiological and functional evaluation using the hospital for special surgery knee score (HSS). (Table 1)

Postoperatively $\mathrm{X}$ - rays were taken to assess the alignment and early mobilization started according to the stability of the fixation. Patients were followed every monthly for examination, HSS (Hospital for special surgery) score and $\mathrm{X}$-rays were taken to assess the union. (Figure 1)

In our study, total number of patients were 50 with a mean age of the 35. $1 \pm 8.3$ years. There were 30 males and 20 females. 40 fractures were due to RTA and 4 due to fall of heavy object both were high energy trauma. 6 were due to accidental fall and all 6 were females more than 50 years old.

In our study out of 50 cases 2 cases of type A1, 4 cases of type A2, 10 cases of type A3, 1 case of type B1, 1 case of type B2, 8 cases of type $\mathrm{C} 1,15$ cases of type $\mathrm{C} 2$ and 9 cases of type C3 were classified by applying the Muller's classification. (Table 2)

Joint mobilization was commenced after suture removal depending on the fracture pattern and the stability of fixation. Joint mobilization was delayed in 5 cases, one due to severe osteoporosis, two due to associated tibial plateau fracture and due to unstable fixation. Non weight bearing for 6 weeks followed by partial weight bearing and full weight bearing was allowed after radiological evidence of union.

All the patients were followed up with regular radiological and functional assessment with a mean follow up of 10. 6 months. Successful fracture union was defined as complete bridging callus in three cortices, together with painless full weight bearing. 

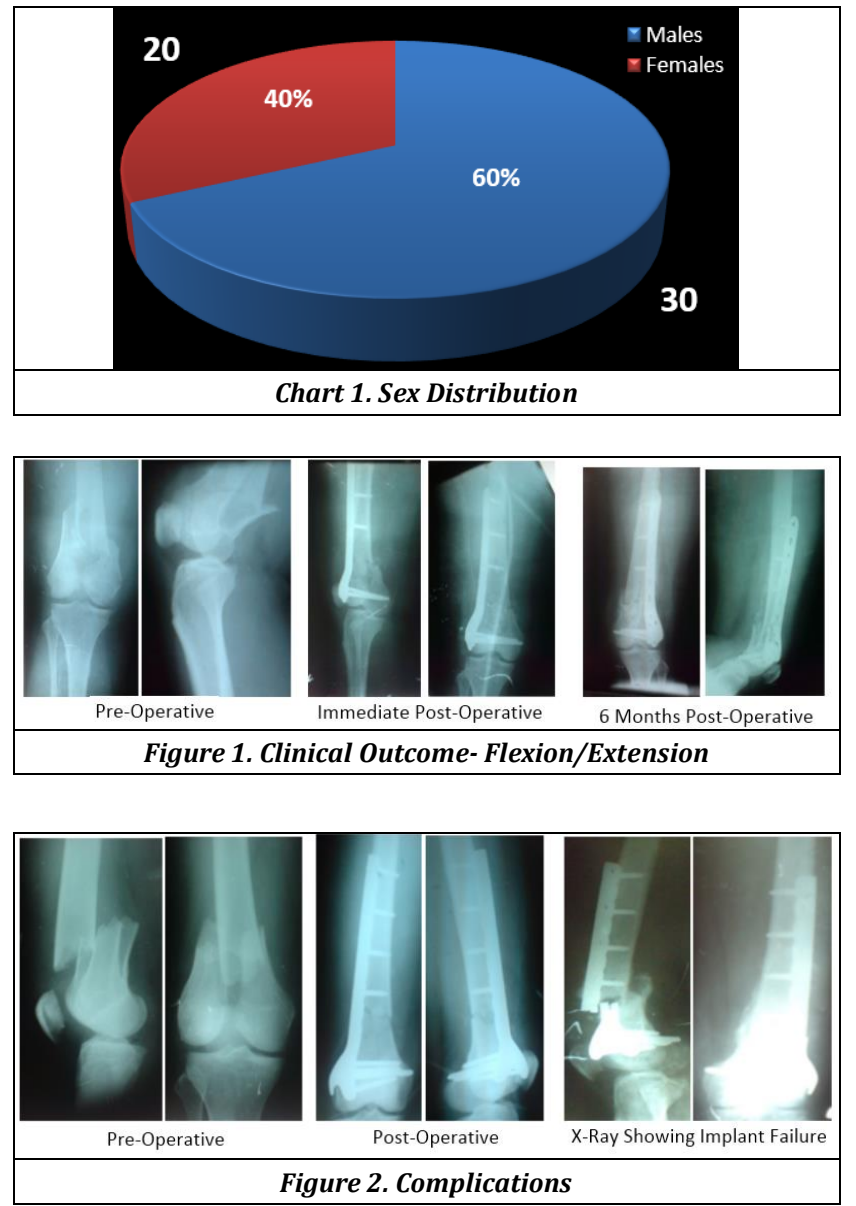

\begin{tabular}{|c|c|c|}
\hline & Variables & Score \\
\hline \multirow{2}{*}{ Pain } & Walking (none to severe) & $15-0$ \\
\hline & At rest (none to severe) & $15-0$ \\
\hline \multirow{7}{*}{ Function } & Walking (unlimited to unable) & $12-0$ \\
\hline & Stairs (normal to with support) & $5-2$ \\
\hline & Transfer (normal to with support) & $5-2$ \\
\hline & $\operatorname{RoM}\left(80^{\circ}-120^{\circ}\right)$ & $10-15$ \\
\hline & Muscle strength (grade 5-0) & $15-0$ \\
\hline & Flexion deformity (none to $>20^{\circ}$ ) & $10-0$ \\
\hline & Instability (none to $>15^{\circ}$ ) & $5-0$ \\
\hline \multirow{5}{*}{ Subtractions } & One cane & 1 \\
\hline & One crutch & 2 \\
\hline & Two crutches & 3 \\
\hline & Extension lag $\left(5^{\circ}-15^{\circ}\right)$ & $2-5$ \\
\hline & Deformity (every $5^{\circ}$ ) & 1 \\
\hline \multicolumn{3}{|c|}{ Table 1. HSS (Hospital for Special Surgery) Score ${ }^{10}$} \\
\hline \multicolumn{3}{|c|}{$\begin{array}{c}\text { Total score: Excellent }=85 \text { points or more, Good }=70-84 \text { points, } \\
\text { Fair }=60-69 \text { points, } \text { Poor }=\text { less than } 60 \text { points. }\end{array}$} \\
\hline
\end{tabular}

\begin{tabular}{|c|c|c|c|c|c|c|c|c|c|}
\hline Type & A1 & A2 & A3 & B1 & B2 & B3 & C1 & C2 & C3 \\
\hline No & 2 & 4 & 10 & 1 & 1 & - & 8 & 15 & 9 \\
\hline \multicolumn{10}{|c|}{ Table 2. Muller's Classification Type } \\
\hline
\end{tabular}

\begin{tabular}{|c|c|c|}
\hline HSS Outcome & No. of Cases & Percentage \\
\hline Excellent & 28 & $56 \%$ \\
\hline Good & 8 & $16 \%$ \\
\hline Fair & 8 & $16 \%$ \\
\hline Failure & 6 & $12 \%$ \\
\hline \multicolumn{3}{|c|}{ Table 3 } \\
\hline
\end{tabular}

\begin{tabular}{|c|c|c|c|c|c|c|c|c|}
\hline 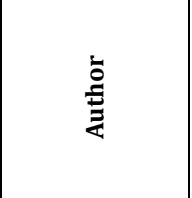 & $\dot{z}$ & 总 & 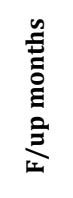 & $\sum_{0}^{0}$ & 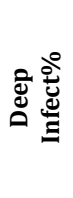 & 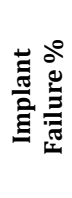 & 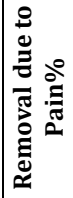 & 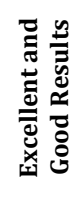 \\
\hline Kregor et al & 66 & 9 & $2-103$ & 3 & 1.5 & - & - & - \\
\hline Schutz et al & 99 & 54 & 13.7 & $0-107$ & 7 & 6 & - & - \\
\hline Markmiller et al & 20 & 57 & 12 & $0-110$ & - & 10 & - & 87.5 \\
\hline Apostolou et al & 19 & 54.5 & 16 & $0-108$ & 5 & 5 & - & 81.25 \\
\hline $\begin{array}{c}\text { Yeap and } \\
\text { Deepak } \\
\text { et al }{ }^{15} \\
\end{array}$ & 11 & 44 & 9.7 & $1-107.7$ & - & 9 & - & 72.7 \\
\hline Our study & 50 & 35.1 & 13.6 & $0-106.8$ & 4 & 8 & 4 & 72 \\
\hline
\end{tabular}

Table 4. Comparison of Results of Distal Femoral Fractures Treated with LCP Obtained by Other Studies ${ }^{16-18}$

\section{RESULTS}

The following were the observations made in the present study. The total number of patients was 50 with 30 males (60\%) and 20 females (40\%) (Chart 1). The youngest age in our study was 19 and the oldest age is 65 . High incidence is found in 21 to 40 years age group with males are more common due to high velocity injuries. In more than 50 years age group females are predominantly affected mainly due to low velocity injuries.

Mode of injury were 40 cases due to RTA (80\%), 6 cases due to accidental fall $(12 \%)$ and 4 case due to fall of heavy object (8\%). The average months of follow up were 10.6 months with longest of 23 months and shortest of 3 months. Successful fracture union was defined as complete bridging callus in three cortices, together with painless full weight bearing. All patients were able to bear full weight postoperatively except for six patients. Excluding these patients, average time to union was 18 weeks with a range from 10 weeks to 36 weeks. Mean Range of motion was $0^{0}$ 106. $8^{0}$. Using the HSS scoring system, there were 28 excellent results, 8 good, 8 fair and 6 failure. Excellent and Good 72\%. (Table 3)

\section{Complications}

Complications included 4 implant failure of which three needed revision and in the other alignment was maintained and hence union achieved with Above Knee Cast application. There was one case of non-union and one case of deep infection which was treated with wound debridement and appropriate antibiotics and bony union obtained after 18 weeks. One patient had knee pain for which implant exit was done and after which he got relieved of pain.

The comparison with other studies for distal femoral LCP has shown similar results (Table 4). The mean range of motion was $0-106.8$ degrees which is similar to the other studies compared. The incidence of deep infection was $4 \%$, with implant failure of $8 \%$ which all are comparable with the various studies. The percentage of patients with excellent and good results was $72 \%$ which is comparable and similar to the 72. $7 \%$ obtained by Yeap and Deepak et al. ${ }^{15}$

\section{DISCUSSION}

Treatment of the Supracondylar fractures of the femur have been a controversial subject over the past two decades. There has been a changing philosophy towards surgical treatment of supracondylar fractures of femur. Close management of these fractures was the treatment of choice until 1970. This 
was due to non-availability of appropriate implants and lack of proper techniques. Apart from the usual problems of confining elderly patient to bed, conservative methods at any age may be complicated by knee stiffness, mal union and nonunion. ${ }^{1}$

The use of fixed angle devices such as condylar blade plate and the dynamic condylar screw (DCS) require certain amount of bone stock present, which limits their use in some fracture types. ${ }^{2}$ This lead to the development of condylar buttress plates for comminuted fractures. ${ }^{3}$ However with standard buttress plating, these fractures often fall into varus deformity. Biomechanical studies revealed that gross loosening of standard condylar buttress plate and DCS occurred because of the toggle at the screw- plate interface. To address these issues, a first generation locking condylar plate was designed. A locking plate decreases the screw-plate toggle and motion at the bone-screw interface and provides more rigid fixation. Rigid fixation is felt to be one key to the successful treatment of these fractures. ${ }^{4}$

So now with the evolution of locking compression plating for distal femoral fractures especially for the comminuted intra articular fractures many of the older demerits could be addressed which includes the increased stability due to locking compression plating principle, multiple screw options in the distal fragment providing option for fixing the multiple fragments restoring the anatomical congruity and providing stable fixation of the distal fragment with the proximal fragment with resulting increased stability allowing for early mobilization. ${ }^{4}$

Current fracture patterns which we encounter are complex comminuted types due to the prevalence of highspeed vehicles mainly due to the high two-wheeler population in countries like India. Improved healthcare results in a longer lifespan and subsequently presents us with more osteoporotic fractures which were previously treated using conservative methods. The LCP is a single beam construct where the strength of its fixation is equal to the sum of all screw-bone interfaces rather than a single screw's axial stiffness and pull-out resistance in unlocked plates. Its unique biomechanical function is based on splinting rather than compression resulting in flexible stabilisation, avoidance of stress shielding and induction of callus formation. It can also be used as biological fixation without disturbing the fracture site. ${ }^{5}$

The Distal Femur-LCP is a further development from the LISS, which was introduced in the mid to late 1990's. The main difference between the Distal Femur-LCP and the LISS is that the LISS utilises an outrigger device for shaft holes, functioning essentially as a locking guide jig, which is attached to the distal part of the plate and guides the placement of the proximal locking screws. The shaft holes on the Distal Femur-LCP are oval allowing for the options of a compression screw or a locking screw. This leads to a more precise placement of the plate, as it is able to be compressed more closely to the bone. 6 Although Distal Femur-LCP is designed to fit the anatomy of the distal femur, we were worried about the fit in our local Asian population where shorter and smaller femurs are the norm. During fixation in delayed cases especially if there was severe comminution maintaining the reduction in good alignment and applying the initial screw were difficult.
The average time of union was 18 weeks which is similar to the other modes of fixation and there is no additional benefit of early healing. However, $72 \%$ of patients had good fracture union and had excellent to good results in HSS score.

Comparable studies utilizing the distal femur LCP demonstrate similar short-term results. Although the followup period of our series was short, studies have shown that early function is comparable to final long-term outcome. The outcome seems to correlate with fracture severity, anatomic reduction, aetiology, bone quality, length of time elapsed from injury to surgery, concomitant injuries and the exact positioning and fixation of the implant. Furthermore, the initial severe concomitant cartilage damage may predispose to early osteoarthritis although there is no evidence of that yet.

Four patients had implant breakage (Figure 2) out of whom one had the fracture alignment maintained and hence he was immobilized in an Above Knee Cast after which fracture got united and Fair result was obtained. The other three patients had displaced fragments for which implant exit and re-surgery was planned.

In one patient who had non-union, initially he had Gustilo's Grade III B compound fracture for which wound debridement and external fixation was done. After that ORIF with LCP was done. There was no evidence of union at 6 months post op. Later for non-union bone grafting was done and fracture union obtained.

One patient was encountered with deep infection which was noticed in the 5th postoperative day for which wound wash was given and infection settled after treating with appropriate antibiotics.

One case had a shortening of $2.5 \mathrm{~cm}$ which was due to multiple procedures for the same fracture with different implants before the application of LCP which resulted in a bone loss. The fracture united well but with shortening.

Varus malalignment was one of the complications which was encountered during the initial phase of the study. In the later phase of the study Varus malalignment was low due to the technique of maintaining gap between the plate and the proximal fragment and hence the good alignment was maintained. Also using lengthier plates rather than using small plates resulted in reduced rate of this complication in the later part of the study.

In Muller's C2 and C3 fractures due to the multiple screw options multiple fragments can be reduced with improved stability which cannot achieved by using the conventional DCS which uses only one large lag screw. 11 Also revision surgery can be done easily in LCP whereas in DCS if a revision surgery is planned the removal of the lag screw leaves a cavity in the condylar area which renders it difficult for fixation and even if fixation is done chances of failure is more due to poor bone stock.

\section{CONCLUSIONS}

The Distal Femur-Locking Compression Plate is a good implant to use for fractures of the distal femur. However, accurate positioning and fixation are required to produce satisfactory results. Our results are encouraging with $72 \%$ of the patients having good to excellent results. Therefore, locking compression plate has a significant advantage with excellent results in treating distal femoral fractures. 


\section{REFERENCES}

[1] Neer CS II, Gratham SA, Shelton ML. Supracondylar fracture of adult femur. A study of 110 cases. J Bone Joint Surg Am 1967;49(4):591-613.

[2] Kapatkin AS. The evolution of AO/ASIF bone plating equipment: Are they better or just different? Vol. 1. University of California, Canine Medicine Symposium, Jun 2008.

[3] Wagner M, Frigg R. Davis AO manual of fracture management. Internal fixators: concepts and cases using LCP and LISS. Department of Surgical \& Radiological Sciences, University of California, Stuttgart, Germany: Thieme 2006.

[4] Egol KA, Kubiak EN, Fulkerson E, et al. Biomechanics of locked plates and screws. J Orthop Trauma 2004;18(8):488-93.

[5] Perren SM. Evolution of the internal fixation of long bone fractures. The scientific basis of biologic internal fixation: choosing a new balance between stability and biology. J Bone Joint Surgery Br 2002;84(8):1093-110.

[6] Stoffel K, Dieter U, Stachowiak G, et al. Biomechanical testing of the LCP-how can stability in locked internal fixators be controlled? Injury 2003;34(Suppl 2):B11B19.

[7] Wagner M. General principles for the clinical use of the LCP. Injury 2003;34(Suppl 2):B31-B42.

[8] Zura RD, Browne JA. Current concepts in locked plating. J Surgical and Orthop Advances 2006;15(3):173-6.

[9] Rabin SI, Thomson JD, Kellam JF. Supracondylar femur workup. Medscape, e-medicine specialities, Updated Oct 13, 2017.
[10] Khan MA, Shafique M, Sahibzada AS, et al. Management of type-a supracondylar fractures of femur with Dynamic Condylar Screw (DCS). Int Journal of Medical Sciences 2006;14(1):44-7.

[11] Canale ST, Beaty JH. Campbell's Operative Orthopaedics. University of Tennese. Vol. $1.11^{\text {th }}$ edn 2004: p. 55-60.

[12] Hoppenfeld S, DeBoer P. Surgical exposure in orthopaedics: the anatomic approach. Vol. 1. $3^{\text {rd }}$ edn. Philadelphia: Lippincott Williams \& Wilkins 2003.

[13] Chapman M, James M. Chapman's Orthopaedic surgery. University of California, Vol. 2. 3rd edn. 2001.

[14] Hansen ST. Rockwood \& Green's Fractures in adults. 6th ed. JBJS 2007;89(3):697-700.

[15] Yeap EJ, Deepak AS. Distal femoral locking compression plate fixation in distal femoral fractures: early results. Malaysian Orthopaedic Journal 2007;1(1):13-7.

[16] Kregor PJ, Stannard J, Zlowodzki M, et al. Distal femoral fixation utilizing the Less Invasive Stabilization System (L. I. S. S. ): the technique and early results. Injury 2001;32(Suppl 3):SC32-SC47.

[17] Schutz M, Mueller M, Krettek C, et al. Minimally invasive fracture stabilization of distal femoral fractures with the LISS: a prospective multicenter study. Results of a clinical study with special emphasis on difficult cases. Injury 2001;32(Suppl 3):SC48-54.

[18] Apostolou CD, Papavasiliou AV, Aslam N, et al. Preliminary results and technical aspects following stabilisation of fractures around the knee with liss. Injury Extra 2005;36:529-36. 